\title{
Penerapan Strategi Pembelajaran Mind Mapping Untuk Meningkatkan Hasil Belajar Siswa Pada Materi "Teks Panjang" Mata Pelajaran Bahasa Indonesia di SDN 173346 Dolok Martumbur Kecamatan Muara Kelas IV T.P 2018/2019
}

\author{
Tinurbaya Lumbangaol \\ SDN 173346 Dolok Martumbur
}

Strategi Mind Mapping adalah pendekatan pembelajaran dalam bentuk visualisasi berupa simbol atau gambar yang dapat digunakan sebagai ganti catatan tertulis dan hasilnya lebih cepat untuk diingat.. Penelitian ini bertujuan untuk mengetahui adanya peningkatan hasil belajar bahasa Indonesia siswa SDN 173346 Dolok Martumbur Kelas IV pada materi 'Teks panjang" melalui Strategi Mind Mapping T.P 2018/2019, termasuk peningkatan aktivitas dan respon belajar siswa terhadap mata pelajaran bahasa Indonesia. Jenis Penelitian yang dilakukan adalah penelitian tindakan kelas yang dilaksanakan dalam 2 siklus. Tiap siklus terdiri dari 4 tahap, yaitu perencanaan, pelaksanaan tindakan, observasi, analisis dan refleksi. Penelitian ini dilaksanakan di SDN 173346 Dolok Martumbur, kecamatan Muara, kabupaten Tapanuli Utara dengan subjek penelitian siswa Kelas IV sejumlah 16 orang. Data aktifitas siswa digali dari hasil obervasi melalui instrumen penilaian aktifitas, data hasil belajar diperoleh dari hasil tes akhir hasil belajar setiap siklus, dan data respon belajar siswa digali dari hasil tes melalui instrumen penilaian respon. Hasil penelitian menunjukkan, (1) pada siklus 1 nilai rata-rata aktifitas belajar siswa 71,88 \%, nilai rata-rata hasil belajar siswa 70,63 $\%$, dan nilai rata-rata respon belajar 72,81, (2) pada siklus 2 , nilai aktifitas belajar siswa ratarata adalah $85,31 \%$, nilai rata-rata hasil belajar 75,93, dan nilai rata-rata respon belajar siswa 85,63. Berdasarkan data hasil belajar pada siklus 1 dan siklus 2 menunjukkan bahwa terdapat peningkatan hasil belajar siswa melalui Strategi Mind Mapping Pada Materi 'Teks panjang" mata pelajaran bahasa Indonesia di SDN 173346 Dolok Martumbur, kec. Muara Kelas IV T.P 2018/2019.

Kata Kunci : Hasil Belajar, Mata Pelajaran bahasa Indonesia, Strategi Mind Mapping

\section{PENDAHULUAN}

Pendidikan pada umumnya, merupakan suatu kegiatan yang universal dalam kehidupan manusia. Dimanapun di dunia ini terdapat masyarakat dan disana pula terdapat pendidikan. Menurut Muhibinsyah dalam Sagala( 2006), pendidikan dapat diartikan sebagai sebuah proses dengan metode-metode tertentu sehingga orang memperoleh pengetahuan, pemahaman, dan cara bertingkah laku yang sesuai dengan kebutuhan. Pendidikan dapat dijadikan sebagai sarana yang tepat untuk menghadapi masa depan serta merupakan salah satu kebutuhan mutlak yang harus dipenuhi sepanjang hayat. Pendidikan dituntut untuk menghasilkan siswa yang berkualitas dan berwawasan internasional serta tidak hanya sekedar memenuhi target kurikulum saja. Untuk mewujudkan hal tersebut pendidikan harus bersifat menyeluruh, baik dari segi kompetensi kognitif, afektif, maupun psikomotor. Selain itu, pembelajaran juga harus dirancang sedemikian rupa sehingga siswa tidak cepat merasa bosan pada saat 
Penerapan Strategi Pembelajaran Mind Mapping Untuk Meningkatkan Hasil Belajar Siswa Pada Materi “Teks Panjang” Mata

Pelajaran Bahasa Indonesia di SDN 173346 Dolok Martumbur Kecamatan Muara Kelas IV T.P 2018/2019

pembelajaran sedang berlangsung. Untuk itu guru harus dapat menciptakan suasana pembelajaran yang kondusif.

Pendidikan merupakan usaha yang sadar dan terencana untuk mewujudkan suasana belajar dan proses pembelajaran agar peserta didik secara aktif mengembangkan potensi dirinya untuk memiliki kekuatan spiritual keagamaan, pengendalian diri, keterampilan, kecerdasan, akhlak mulia serta keterampilan yang diperlukan dirinya, masyarakat, bangsa, dan negara. (Undang-Undang RI No. 20 Tahun 2003). Oleh karena itu pengembangan pendidikan harus dilakukan untuk meningkatkan kualitas pendidikan suatu bangsa. Kemajuan pendidikan harus dikembangkan dengan baik agar dapat meningkatkan mutu pendidikan dan juga dapat meningkatkan harkat dan martabat suatu bangsa.

Melalui pendidikan, tercipta manusia yang cerdas, trampil, berwawasan luas, disiplin beriman, bertaqwa serta bertanggung jawab didalam kehidupan. Untuk dapat mencapai tujuan pendidikan tersebut, sekolah sebagai salah satu intitusi pendidikan formal memiliki tanggung jawab yang besar untuk mewujudkannya. Upaya untuk mewujudkan itu menjadi tanggung jawab semua stakeholder pendidikan yang salah satunya adalah komponen guru sebagai ujung tombak pendidikan.

Menurut Hammalik (1994), guru bertanggung jawab melaksanakan kegiatan pendidikan di sekolah dalam arti memberikan bimbingan dan pengajaran kepada para siswa". Guru harus dapat melakukan suatu inovasi yang menyangkut tugasnya sebagai pendidik yang berkaitan dengan tugas mengajar siswa. Inovasi-inovasi yang dilakukan guru dalam tugasnya sebagai pendidik diharapkan mampu meningkatkan prestasi belajar siswa. Mengingat bahwa guru juga memberi pengaruh terhadap prestasi belajar siswa.

Persoalan penerapan strategi atau pendekatan pembelajaran menjadi salah faktor yang dapat mempengaruhi hasil belajar. Keberhasilan siswa dalam proses pembelajaran dapat dipengaruhi oleh faktor dari dalam individu maupun dari luar individu. Faktor dari dalam individu meliputi fisik dan psikis, contoh faktor psikis diantaranya adalah motivasi. Motivasi belajar siswa yang tinggi dapat menunjang keberhasilan belajar, akan tetapi motivasi belajar siswa yang rendah merupakan hambatan yang dapat berakibat pada hasil belajar rendah. Untuk itu guru harus dapat memilih strategi atau strategi yang tepat agar tercipta situasi pembelajaran yang menarik sehingga dapat menumbuhkan motivasi belajar dan keberhasilan siswa dalam belajar tercapai.

Pendekatan pembelajaran guru yang monoton adalah suatu hal yang masih banyak ditemukan di sekolah termasuk dalam pembelajaran bahasa Indonesia. Padahal pembelajaran bahasa Indonesia diantaranya bertujuan agar peserta didik memiliki kemampuan berkomunikasi secara efektif dan efisien dengan etika yang berlaku secara lisan maupun tulisan, sehingga bahasa Indonesia dapat digunakan dengan tepat dan kreatif. Untuk mewujudkan tujuan tersebut maka tentu diperlukan berbagai variasi pendekatan pembelajaran pembelajaran agar lebih menarik (Sumarni, 2012). 
Oleh karena itu, para guru dituntut untuk lebih dapat kreatif untuk menunjang keberhasilan pembelajaran bahasa Indonesia. Namun, kenyataannya para guru masih menggunakan strategi ceramah dalam menyampaikan materi, sehingga pembelajaran bahasa Indonesia terlihat monoton dan bersifat pasif karena hanya berpusat pada guru. Pada pembelajaran bahasa Indonesia, hal yang perlu diubah adalah pandangan dan sikap para peserta didik yang sering menganggap bahwa belajar bahasa Indonesia merupakan hal yang sangat membosankan. Mengingat betapa pentingnya penggunaan bahasa, pembelajaran bahasa harus dilakukan secara tepat (Sumarni, 2012).

Kumaradivelu dalam Muhibbin (2008) menjelaskan perlunya prosedur yang harus diterapkan seorang guru ketika mengajar di dalam kelas, yaitu: memodifikasi materi dan memfasilitasi aktivitas para siswa. Modifikasi materi mengacu pada cara guru menyajikan materi yang dapat menarik siswa menjadi termotivasi untuk belajar, sehingga diperlukannya strategi pembelajaran yang tepat. Guru juga harus memfasilitasi interaksi para siswa, misalnya memberikan kesempatan kepada siswa untuk bekerja sama dalam penyelesaian tugas.

Salah satu strategi pembelajaran yang dapat dilakukan dalam pelajaran bahasa Indonesia adalah strategi pembelajaran mind map. Menurut DePorter \& Hernacki (2008), mind mapping juga dapat disebut dengan peta pikiran. Mind mapping menggunakan pengingat-pengingat visual dan sensorik dalam suatu pola dari ide-ide yang berkaitan.

Mind mapping merupakan teknik catatan demi catatan demi membantu peserta didik menggunakan seluruh potensi otak agar optimum dan meningkatkan kemampuan koneksi bahasa Indonesia. Koneksi bahasa Indonesia merupakan bagian penting yang harus mendapatkan penekanan disetiap jenjang pendidikan. Koneksi bahasa Indonesia adalah keterkaitan antara topik bahasa Indonesia, keterkaitan antara bahasa Indonesia dengan disiplin ilmu yang lain dan keterkaitan bahasa Indonesia dengan dunia nyata atau dengan kehidupan sehari-hari. Caranya yaitu dengan menggabungkan kerja otak kanan dan otak kiri. Dengan strategi pembelajaran mind map ini peserta didik dapat meningkatkan daya ingat dengan baik.

Strategi pembelajaran mind mapping dalam pembelajaran bahasa Indonesia menjadi salah satu pendekatan pembelajaran yang sangat jarang diterapkan di SDN 173346 Dolok Martumbur, termasuk pada mata pelajaran bahasa Indonesia. Fakta nilai rata-rata mid semester ganjil siswa kelas IV T.P 2018/2019 yang lalu menunjukkan bahwa 20 \% nilai bahasa Indonesia di kelas IV masih di bawah nilai KKM yaitu sebesar 70. Data ini menunjukkan bahwa hasil belajar siswa di kelas IV dalam mata pelajaran bahasa Indonesia masih belum maksimal. Menurut pengamatan penulis, kondisi ini salah satunya dipengaruhi oleh faktor kurangnya _motivasi dan antusiasme siswa dalam belajar bahasa Indonesia Untuk itu perlu diterapkan suatu strategi yang dapat menambah motivasi dan antusiasme siswa dalam belajar bahasa Indonesia. 
Menurut Hisyam, dkk (2008), dengan strategi pembelajaran mind map, siswa akan lebih mudah memahami setiap konsep yang inklusif dan konsep-konsep yang kurang inklusif, dan membantu otak untuk mengatur, mengingat, membandingkan, dan membuat hubungan materi. Bagi guru, dapat membantu memahami macam-macam konsep yang ditanamkan pada topik yang lebih besar.

Dengan menerapkan strategi pembelajaran mind map dalam pembelajaran bahasa Indonesia diharapkan dapat lebih menggairahkan suasana pembelajaran sehingga siswa lebih termotivasi dalam belajar yang pada akhirnya dapat meningkatkan hasil belajar.

\section{METODOLOGI PENELITIAN}

Penelitian ini merupakan penelitian tindakan kelas (PTK) yang dilaksanakan terdiri dari 2 siklus dan tiap siklusnya terdiri dari 2 kali kegiatan tatap muka, dengan masing - masing tatap muka selama 2 jam pelajaran (2x40 menit). Setiap siklus terdiri dari 4 tahap, yaitu perencanaan, pelaksanaan, pengamatan, dan refleksi. Subjek penelitian ini adalah siswa kelas IV SDN 173346 Dolok Martumbur Kabupaten Tapanuli Utara T.P 2018/2019 yang berjumlah 16 orang. Karakteristik responden adalah kelompok siswa yang beragam dari segi jenis kelamin dan tingkat hasil belajarnya. Adapun Teknik pengumpulan data dilakukan dengan teknik observasi, tes dan angket. Analisis digunakan untuk menjawab masalah penelitian yaitu apakah Pembelajaran dengan menerapkan strategi strategi pembelajaran mind map dapat meningkatkan hasil belajar siswa dalam materi "teks panjang". Setelah semua data terkumpul, kemudian dianalisis

\section{HASIL PENELITIAN DAN PEMBAHASAN}

Sesuai dengan pelaksanaan penelitian tindakan kelas siklus I dan siklus II maka diperoleh data sebagai berikut :

1. Data peningkatan aktivitas belajar siswa terhadap mata pelajaran bahasa Indonesia pada siklus | dan siklus ||.

Tabel 4. 7 Persentase peningkatan aktivitas belajar siswa terhadap mata pelajaran bahasa Indonesia pada siklus I dan siklus ||

\begin{tabular}{|l|c|l|c|l|l|}
\hline \multirow{2}{*}{ Data Yang Diperoleh } & \multicolumn{4}{|c|}{ Hasil } & \multirow{2}{*}{ Peningkatan } \\
\cline { 2 - 5 } & \multicolumn{2}{|c|}{ Siklus I } & \multicolumn{2}{|c|}{ Siklus II } & \\
\cline { 2 - 5 } & Frek & $\%$ & Frek & $\%$ & \\
\hline$\sum$ Siswa Yang Tuntas & 11 & 68,75 & 14 & 87,5 & 13,44 \\
\hline
\end{tabular}

Indikator $\geq 85 \%$ 


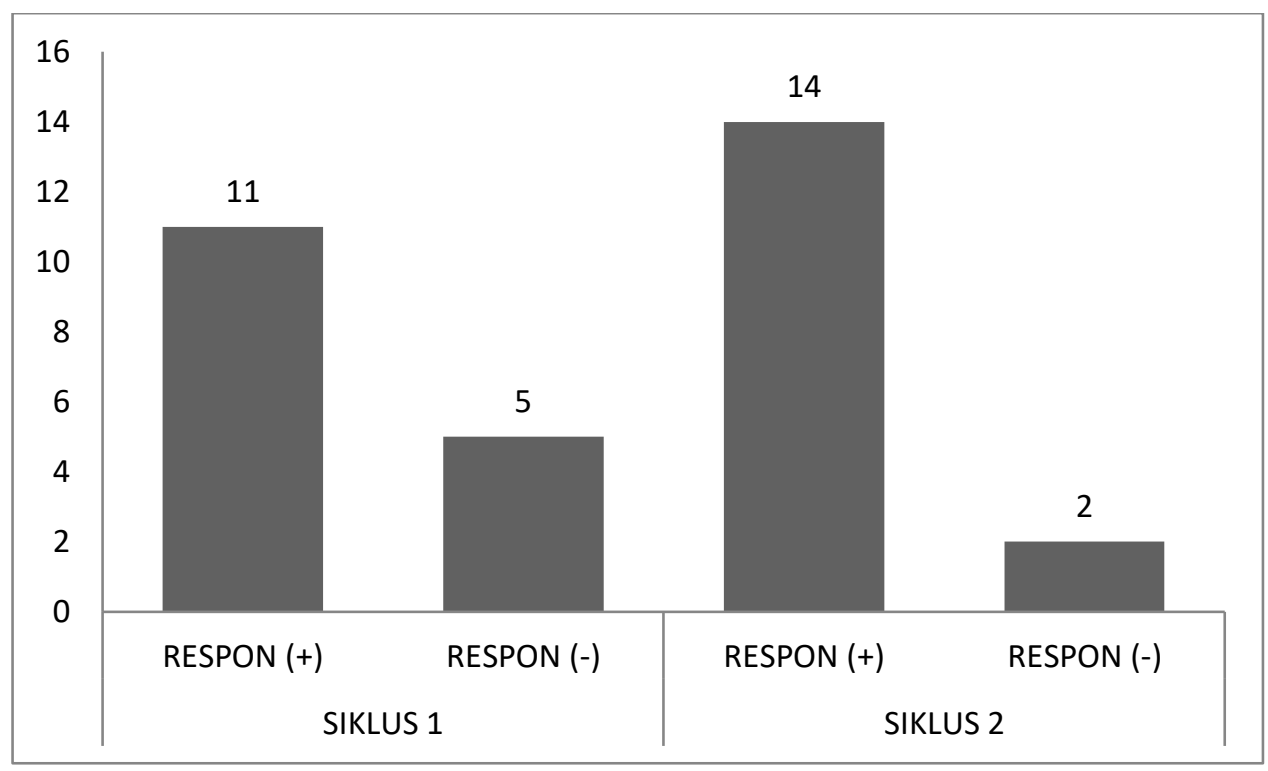

Grafik 1. 1. Grafik peningkatan aktifitas belajar bahasa Indonesia siklus 1 dan siklus 2

Dari tabel 4.7 dan grafik 1.1 di atas dapat dilihat secara jelas bahwa aktivitas siswa dengan menggunakan pembelajaran strategi mind map dari siklus I sampai siklus II mengalami peningkatan yaitu sebesar $6,67 \%$. Hal ini disebabkan dengan pembelajaran strategi mind map siswa lebih memberi kesempatan siswa untuk aktif berdiskusi dan bekerjasama dalam kelompok.

2. Data peningkatan hasil belajar siswa terhadap mata pelajaran bahasa Indonesia pada siklus I dan siklus II.

Tabel 4. 8 Persentase peningkatan hasil belajar bahasa Indonesia pada siklus I dan siklus II

\begin{tabular}{|l|c|c|c|c|c|}
\hline \multirow{3}{*}{ Data Yang Diperoleh } & \multicolumn{4}{|c|}{ Hasil } & \multirow{2}{*}{ Peningkatan } \\
\cline { 2 - 5 } & \multicolumn{2}{|c|}{ Siklus I } & \multicolumn{2}{|c|}{ Siklus II } & \\
\cline { 2 - 5 } & Frek & $\%$ & Frek & $\%$ & \\
\hline$\sum$ Siswa Yang Tuntas & 10 & 62,50 & 14 & 87,5 & $5,31 \%$ \\
\hline
\end{tabular}

Indikator $\geq 75 \%$ 


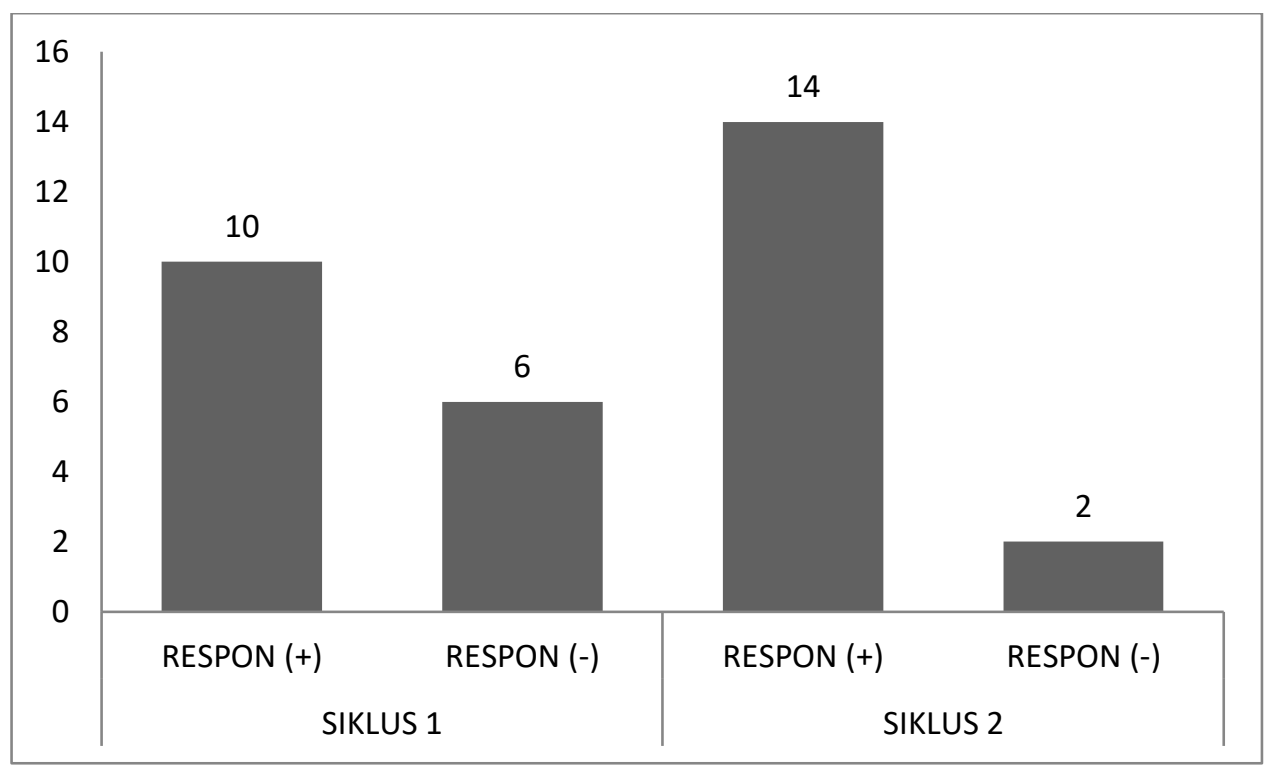

Grafik 1. 2. Grafik peningkatan hasil belajar bahasa Indonesia siklus 1 dan siklus 2

Dari tabel 4.8 dan grafik 1.2 diatas dapat dilihat secara jelas bahwa hasil belajar bahasa Indonesia siswa SDN 173346 Dolok Martumbur kelas IV dengan menggunakan strategi pembelajaran mind map dari siklus I sampai siklus II mengalami peningkatan sebesar 16,67 \%. Pada siklus 2, jumlah siswa yang memperoleh nilai KKM ( $\geq 70 \%)$ mencapai 9 siswa dan siswa yang tidak tuntas 2 orang $(87,5 \%)$.

Peningkatan ini dipengaruhi oleh faktor dimana kegiatan pembelajaran dengan strategi pembelajaran mind map dapat merangsang siswa belajar dan mempercepat daya tangkap otak siswa dalam belajar karena pembelajaran dikemas lebih menarik dan menyenangkan sehingga hasil belajar siswa meningkat.

3. Data peningkatan respon belajar siswa terhadap mata pelajaran bahasa Indonesia pada siklus I dan siklus II.

Tabel 4. 9 Persentase peningkatan respon belajar siswa terhadap mata pelajaran bahasa Indonesia pada siklus I dan siklus ||

\begin{tabular}{|c|c|c|c|c|c|}
\hline \multirow{2}{*}{ Data Yang Diperoleh } & \multicolumn{4}{|c|}{ Hasil } & \multirow{2}{*}{ Peningkatan } \\
\cline { 2 - 5 } & \multicolumn{2}{|c|}{ Siklus I } & \multicolumn{2}{|c|}{ Siklus II } & \\
\cline { 2 - 5 } & Frek & $\%$ & Frek & $\%$ & \\
\hline $\begin{array}{l}\text { } \\
\text { Respon piswa Yang Memberi }\end{array}$ & 11 & 68,75 & 13 & 81,25 & $12,81 \%$ \\
\hline
\end{tabular}

Indikator $\geq 85 \%$ 


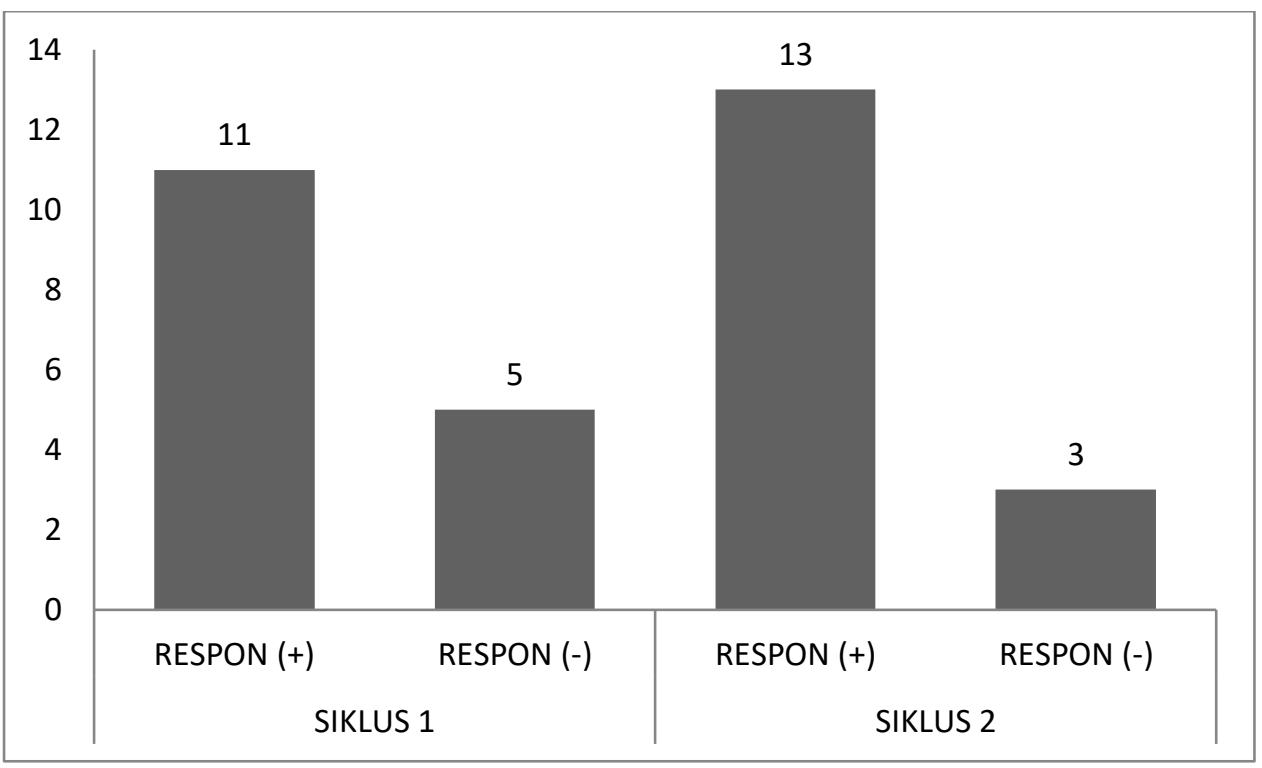

Grafik 1. 3. Grafik peningkatan respon belajar bahasa Indonesia siklus 1 dan siklus 2

Dari tabel 4.9 dan grafik 1.3 di atas menunjukan bahwa respon belajar bahasa Indonesia dengan menggunakan pembelajaran strategi mind map dari siklus I sampai siklus II mengalami peningkatan sebesar 6,67 \%. Hal ini disebabkan dengan pembelajaran strategi mind map siswa lebih senang dalam belajar dan siswa juga merasa pembelajaran strategi pembelajaran mind map merupakan hal yang baru bagi mereka.

Dari pembahasan hasil penelitian selama siklus I dan siklus II nampak bahwa hasil belajar, aktivitas siswa maupun respon siswa pada pembelajaran bahasa Indonesia materi "teks panjang' dengan strategi mind map mengalami peningkatan yang cukup signifikan.

Dengan demikian hipotesis penelitian ini yang mengatakan bahwa "Penerapan pembelajaran strategi mind map dapat meningkatkan hasil belajar siswa siswa pada materi "teks panjang'" mata pelajaran bahasa Indonesia di SDN 173346 Dolok Martumbur kelas IV dapat diterima.

\section{KESIMPULAN}

Berdasarkan hasil pembahasan yang telah dilakukan maka dapat disimpulkan bahwa : Terdapat peningkatan aktivitas belajar siswa melalui strategi pembelajaran mind map pada materi "teks panjang' mata pelajaran bahasa Indonesia di SDN 173346 Dolok Martumbur kelas IV T.P 2018/2019. Terdapat peningkatan hasil belajar siswa melalui strategi pembelajaran mind map pada materi "teks panjang' mata pelajaran bahasa Indonesia di SDN 173346 Dolok Martumbur kelas IV T.P 2018/2019. Terdapat peningkatan respon belajar siswa melalui strategi pembelajaran mind map pada materi "teks panjang' mata pelajaran bahasa Indonesia di SDN 173346 Dolok Martumbur kelas IV T.P 2018/2019. Penulis Menyarankan kepada guru-guru kelas khususnya ketika mengajar mata pelajaran bahasa Indonesia agar strategi pembelajaran mind map dapat dijadikan sebagai salah satu pendekatan pembelajaran 
dalam rangka menciptakan suasanan pembelajaran yang menyenangkan sekaligus dapat meningkatkan hasil belajar. Sekolah memberikan fasilitas bagi guru dan siswa seperti peralatan gambar untuk menunjang penerapan strategi pembelajaran mind map di dalam kelas.

\section{DAFTAR PUSTAKA}

Arikunto, S. 2006. Penelitian Tindakan Kelas. Jakarta: PT Bumi Aksara

Buzan, T. 2007. Buku Pintar Mind Map Untuk Anak Agar Anak Pintar di Sekolah. Jakarta : PT. Gramedia Pusaka Utama.

Depdiknas, 2007. Undang-Undang Sistem Pendidikan Nasional. Jakarta. Depdiknas

Deporter, B dan Hernacki, M. 2000. Quantum Dan Learning Di Ruang - Ruang Kelas. Bandung. Kaifa.

Dimyati dan Mudjiono. 2009. Belajar \& Pembelajaran. Jakarta : Rineka Cipta.

Hamalik, O. 1994. Kurikulum dan Pembelajaran. Bandung: Bumi Aksara.

Hisyam, Z, dkk, 2008. Strategi Pembelajaran Aktif. Yogyakarta: Pustaka Insan Madani.

Kemdikbud, 2014. Buku Guru Bahasa Indonesia. Jakarta. Kemdikbud.

Muhibbin S. 2008. Psikologi Pendidikan dengan Pendekatan Baru. Bandung: Remaja Rosdakarya

Permendiknas Nomor 22 Tahun 2006 tentang Standar Isi.

Permendiknas Nomor 41 Tahun 2007 tentang Standar Proses.

Pringgodigdo, A. G, dkk. 1993. Ensiklopedi Umum, Yogyakarta: Yayasan Kanisuius

Purwanto, N. 2006. Prinsip-Prinsip dan Teknik Evaluasi Pengajaran. Bandung: PT Remaja Rosdakarya.

Rohani, A. 1991. Pengelolaan Pengajaran. Jakarta : Rineka Cipta.

Siberman, M. 2002. Active Learning 101 Strategi Pembelajaran Aktif. Yogyakarta: Yappendis.

Somantri, M. N. 2001. Menggagas Pembaharuan Pendidikan. Bandung: PT Remaja Rosdakarya.

Sudjana, Nana, 2005, Dasar-dasar Proses Belajar, Bandung: Sinar Baru.

Sumarni. 2012. Strategi-Strategi Pembelajaran Geografi. Malang: Aditya Media

Suryaman, M. 2009. Panduan Pendidik dalam Pelajaran Bahasa Indonesia. Jakarta. Pusat Perbukuan Departemen Pendidikan Nasional.

Undang-Undang RI No. 20 Tahun 2003. Sistem Pendidikan Nasional. Depdikbud. Jakarta.

Wiranti, R. Meningkatkan Kreatifitas Anak Usia Dini Melalui Peta Pikiran, Diakses tanggal 30 Januari 2014

Zaini, M. F. (2019). The Implementation Of Learning Management In Class VIII Madrasa Tsanawiyah Islamiyah (Mts) Ypi Batangkuis. International Conference on Islamic Educational Management (ICIEM). 